\section{Análisis de las relaciones entre Estados Unidos y Haití (1915-2015): notas para pensar la dialéctica del imperialismo en el Caribe}

\section{Analysis of the relationship between the United States of America and Haiti (1915-2015): notes for thinking about the dialectics of imperialism in the Caribbean}

DOI: 10.5752/P.2317-773X.2017v5.n1.p103

Fernando Romero Wimer ${ }^{1}$

Paula Fernández Hellmund²

Karen Dos Santos Honório ${ }^{3}$

\begin{abstract}
RESUMEN
Desde la invasión a Haití en 1915 por parte de los Estados Unidos, se puede observar una estrecha vinculación de las acciones políticas y militares de la potencia norteamericana en el país caribeño, en convergencia con sus intereses económicos y sus pretensiones imperialistas. Este artículo tiene por objetivo analizar dialécticamente esta relación a través de su historia considerando: las particularidades de las inversiones de capitales estadounidenses, la estructura de su comercio exterior, la política de intervención y asistencia militar norteamericana y el juego de intereses políticos en el ámbito doméstico de Haití en los últimos 100 años. Paralelamente, el texto parte de una exposición que establece un marco teórico marxista mediante el cual se interpreta el proceso histórico analizado a partir de una perspectiva que asume como vértice la dependencia haitiana y la dominación imperialista norteamericana, puntualizando la política de los Estados Unidos en Haití dentro del esquema estratégico de su política global y, sobre todo, de la región del Caribe en los últimos años.
\end{abstract}

Palabras-clave: Haití. Estados Unidos. Imperialismo. Caribe.

\section{AbSTRACT}

Since the invasion of Haiti in 1915 by the United States, a close relationship of the political and military actions of the U.S. power in the Caribbean country, together with its economic interests and imperialist ambitions, has been observed. The aim of this article is to dialectically analyze this relationship throughout its history, considering: the characteristics of U.S. capital investments, the structure of its foreign trade, its policy on military intervention and assistance and the political interests in Haiti's domestic environment in the last 100 years. Moreover, our text first presents a Marxist theoretical framework by which the analyzed historical process is interpreted from a perspective whose angle is Haitian dependency and the U.S. imperialist domination, focusing on the U.S. policy in Haiti within the strategic scheme of its global policy and, especially, towards the Caribbean region in the last few years.
1. Doctor en Historia. Profesor de la Carrera de Relaciones Internacionales e Integración de la Universidade Federal da Integração Latino-Americana (UNILA), Brasil. Coordinador del Grupo Interdisciplinar de Estudos e Pesquisa sobre Capitais Transnacionais, Estado, classes dominantes e conflitividade na América Latina e Caribe (GIEPTALC). Investigador del Centro Interdisciplinario de Estudios Agrarios (CIEA) de la Universidad de Buenos Aires (UBA) y director del Colectivo de Estudios e Investigaciones Sociales (CEISO). Contato: fernando. romero@unila.edu.br.

2. Dra. en Antropología. Profesora de la Carrera de Relaciones Internacionales e Integración de la UNILA, Brasil. Investigadora del GIEPTALC y del CEISO. Coordinadora del Observatorio Social de América Central e Caribe (OSACC). Contato: paula.fernández@unila.edu.br.

3. Master en Relaciones Internacionales. Profesora de la Carrera de Relaciones Internacionales e Integración de la UNILA, Brasil. Contato: karen.honorio@ unila.edu.br.

Key-words: Haiti. United States of America. Imperialism. Caribbean. 
Introducción

Desde la invasión a Haití en 1915 por parte de los Estados Unidos, se puede observar una estrecha vinculación de las acciones políticas y militares de la potencia norteamericana en el país caribeño, en convergencia con sus intereses económicos y sus pretensiones imperialistas. Este artículo tiene por objetivo analizar dialécticamente esta relación considerando: las particularidades de las inversiones de capitales estadounidenses, su incidencia en el comercio exterior, la política de intervención y asistencia militar norteamericana, y el juego de intereses políticos en el ámbito doméstico de Haití en los últimos cien años. Paralelamente, el texto recurre a un marco teórico a través del cual se interpretan los datos analizados a partir de una perspectiva amplia, puntualizando la política de los Estados Unidos en Haití dentro del esquema estratégico de su política global y, sobre todo, de la región del Caribe en los últimos 30 años.

Inicialmente, por razones de pertinencia temática, junto con nuestra caracterización del fenómeno imperialista, describimos esquemáticamente la incidencia de la supremacía estadounidense y la inserción dependiente de Haití en el desarrollo desigual latinoamericano.

Dialéctica del imperialismo y la dependencia

El imperialismo constituye una fase específica del desarrollo del capitalismo a escala planetaria (LENIN, 1916). Tras el devenir de los procesos de descolonización del siglo XX, en el momento actual, dicho fenómeno va acompañado por una generalización de la dependencia como forma esencial de subordinación nacional. Desde una perspectiva marxista-leninista, la dependencia no es sólo la subordinación externa que guardan los países al imperialismo sino también específicas relaciones internas de explotación (MARINI, 1973).

Frente a esta conceptualización, el imperialismo contemporáneo presenta como características generales: a) la formación de monopolios y oligopolios (a través de la concentración y centralización de la producción, la propiedad de los medios de producción y distribución, los conocimientos y la tecnología, y el capital); b) el predominio del capital financiero sobre el conjunto de la economía; c) la preponderancia de la exportación de capitales por sobre la exportación de productos; d) el reparto del mundo entre grandes empresas y potencias capitalistas; e) la penetración ideológica simultánea en el ámbito educativo, instituciones de la sociedad civil y medios de información de masas tanto de las naciones imperialistas como en los países dependientes; y f) la extracción de plusvalía de los países dependientes y expropiación masiva en un contexto de universalización de las relaciones capitalistas de producción (ROMERO, 2015).

A su vez, es apropiado contemplar algunas facetas específicas presentes en la historia más reciente; a) la supremacía económica, política y militar de los Estados Unidos; b) la formación de potencias capitalistas sobre la base del cambio de carácter de países socialistas; c) el ascenso de países y burguesías rezagadas a condiciones de nuevas potencias emer- 
gentes; y d) la materialización de un proceso de desarrollo desigual interno de los países capitalistas (ROFMAN, 1974).

Vale señalar que la supremacía de la potencia norteamericana tiene sus raíces en el sistema de Bretton Woods, el Fondo Monetario Internacional (FMI), el Banco Mundial y el Acuerdo General de Comercio y Aranceles o GATT (sigla en inglés de General Agreement on Tariffs and Trade) en 1947 (WOOD, 2005). "Los Estados Unidos emergieron de la Segunda Guerra Mundial no sólo como la mayor potencia económica sino además con la principal industria militar del mundo" (ROMERO, 2015, p. 67). El complejo militar-industrial está directamente ligado al Departamento de Defensa, generándose intereses económicos y políticos que favorecen el mantenimiento de su carrera armamentística (YARMOLINSKY, 1971).

En 1949, a través de la Organización de Tratado del Atlántico Norte (OTAN), la potencia norteamericana materializó su alianza militar en tiempos de la Guerra Fría con los países capitalistas de Europa occidental y Canadá. En este marco, se reservó los principales cargos militares de la coalición.

El imperialismo estadounidense "ha apoyado diplomática, militar y económicamente a diferentes dictaduras militares, y contribuido con diferentes golpes militares, acciones desestabilizadoras e intervenciones militares directas" (ROMERO, 2015, p. 67). El proyecto de supremacía de la doctrina militar norteamericana tiene por objeto no sólo disuadir un ataque sino prevenir la emergencia de cualquier rivalidad. Esta superioridad militar es ejercida directamente sobre sus principales aliados que también son parte de sus principales competidores económicos. Por lo tanto, los Estados Unidos pueden ejercer sin ningún tipo de restricciones ese enorme poder militar para defender sus intereses económicos.

En la actualidad, los Estados Unidos tienen unas 800 bases militares en el mundo y mantiene distintas concentraciones de fuerzas militares en aproximadamente 140 países. Sin embargo, no se puede decir que controla la totalidad de éstos por medio de regímenes títeres, ni que su predominio se expresa igual que los imperios comerciales que prevalecían por medio de la fuerza y por un avanzado desarrollo naval. Tampoco su dominio se ejerce a través de la explotación económica de colonias. Bajo el capitalismo las medidas de coerción son impersonales, no parecen impuestas por los seres humanos sino por los mercados. Por las mismas razones, bajo el imperialismo capitalista contemporáneo es más difícil de lo que era en los antiguos imperios coloniales detectar la transferencia de riqueza de los países más débiles a las naciones más poderosas. De todas maneras, el capital requiere apoyarse en fuerzas extra-económicas (el poder político, militar, diplomático y cultural), y estas son, al igual que en el pasado, suministradas fundamentalmente por el Estado. Lo cual lleva a contradecir las posiciones que consideran que el capital ha minimizado la injerencia controladora del Estado, y a analizar cuál es el papel de los diferentes Estados en este escenario (WOOD, 2005).

Por otra parte, debemos señalar que una de las características de la economía estadounidense es su constante déficit de la balanza comercial y de pagos. La explicación de este fenómeno está vinculada particularmente con el incremento de las importaciones, en ocasiones provenientes de empresas filiales de capitales norteamericanos (SÁNCHEZ TABARES; 
ELÍAS MORENO, 2007), con el fin de reducir el costo de la fuerza de trabajo y el valor de los insumos industriales. Al mismo tiempo, hay que considerar el ingreso de capitales del exterior "atraídos por la seguridad, la liquidez y los altos retornos comparativos que se obtienen al participar en los mercados financieros norteamericanos y en la economía norteamericana en general" (PANITCH; GIDIN, 2005, p. 100). Lo cual se vincula a que las letras del Tesoro de Estados Unidos pasaron a constituir una reserva monetaria mundial. De esta forma, una caída del dólar sería contenida por los tenedores de dólares externos con el fin de no ver devaluados sus activos en dólares.

Pasemos ahora a considerar las características específicas de Haití en el contexto del desarrollo desigual de los países latinoamericanos y el escenario mundial bajo la égida del imperialismo capitalista.

La dinámica capitalista configura un desarrollo desigual y combinado entre los territorios (TROTSKY, 2006), el cual no sólo se verifica entre naciones imperialistas y países dependientes sino que tiene manifestaciones tanto al interior de cada sociedad como en el plano internacional entre los propios países dependientes y al interior de la cadena de potencias imperialistas (ACOSTA, 1973).

Los procesos de concentración y centralización del capital y la producción operan como fuerza explicativa para configurar estos escenarios en contradicción. Haití ha debido padecer un insuficiente desarrollo agrario e industrial, déficit en sus balanzas comercial y de pagos, insuficiencia tecnológica y de infraestructura, persistente endeudamiento, la dependencia de inversiones extranjeras y de ingresos en concepto de "ayuda humanitaria” y una economía colapsada.

Este panorama es acompañada por la condición de Haití de ser la economía más pobre del continente con un $75 \%$ de la población viviendo en condiciones de pobreza, precarios sistemas de salud y educación con un $52 \%$ de analfabetismo, miserables vías de acceso al agua potable, elevados niveles de mortalidad materna infantil, una limitada esperanza de vida de la población y una significativa corriente emigratoria que procura mejores circunstancias de vida y trabajo en otros países (LORENZO; REINOSO, 2011).

Por lo tanto, la situación haitiana contrasta con el poderío económico de los Estados Unidos pero también con el dinamismo de la economía de República Dominicana. A ambas naciones se ha dirigido principalmente la migración haitiana (CASTOR, 1983), constituyendo, además, los territorios de origen de sus principales importaciones y aprovisionamiento de remesas (LORENZO; REINOSO, 2011).

Asimismo, debemos destacar algunas razones del interés del capital imperialista en Haití y la consideración de algunos elementos que explican su inserción subordinada en el sistema capitalista internacional. A saber, en los últimos años se destacan: a) recursos energéticos y riquezas del subsuelo haitiano; b) actividades de reconstrucción al servicio del imperialismo; c) disuadir la nutrida emigración de Haití hacia los Estados Unidos; d) establecer maquilas para aprovechar la fuerza de trabajo barata y los menores costos de producción; e) convertir a Haití en un punto geoestratégico sobre el cual poder operar fuerzas militares y de inteligen- 
cia contra el gobierno cubano y el movimiento bolivariano de Venezuela (CANTOR; NOVOA, 2014).

En el trascurso de la exposición de este estudio serán presentadas otras postulaciones a cerca del imperialismo estadounidense y de la dependencia haitiana.

Primeros pasos del imperialismo estadounidense

y la dependencia capitalista haitiana (1915-1934)

Haití proclamó su independencia en 1804, fue la primera república americana que abolió la esclavitud y el primer país latinoamericano que se emancipó de su metrópoli colonial, el segundo de las Américas luego de Estados Unidos. Vale destacar que, a poco de su nacimiento como Estado, la nación caribeña comenzó a estar endeudada con Francia. ${ }^{4} \mathrm{Si}$ tuación devenida por el compromiso de resarcir a su antigua metrópoli colonial de la privación de sus esclavos, que pasaron a ser ciudadanos de la nueva república (LORENZO; REINOSO, 2011).

Los Estados Unidos fueron protagonistas en ese proceso de dominación de Haití por el imperialismo. Un hito en las relaciones entre el país caribeño y la potencia norteamericana fue la invasión de 1915 y debe ser comprendida bajo el velo de la Doctrina Monroe y del Corolario Roosevelt. ${ }^{5}$ La Doctrina Monroe, sintetizada en la idea de "América para los americanos", es la base de la política externa de los Estados Unidos en el período que va desde mediados del siglo XIX hasta el decenio de 1930. Ella se inserta en las disputas interimperialistas de Estados Unidos con las potencias europeas - principalmente Gran Bretaña, Francia y Alemania en América Latina y en el Caribe.

Entre 1915 y 1934, Haití fue ocupado por una invasión estadounidense que tenía por objetivos controlar la vida política interna ante un clima de inestabilidad institucional y agitación social, cerciorar puntos geoestratégicos y asegurar los intereses económicos norteamericanos en el país caribeño. ${ }^{6}$ Los estadounidenses consiguieron imponer a Philippe Sudre Dartiguenave (1915-1922) - un presidente funcional al capital estadounidense -, disolver el ejército haitiano y la sanción de una nueva constitución que legalizó las adquisiciones de tierra por parte de extranjeros. En 1918, surgiría una resistencia encabezada por Charlemagne Péralte contra los intentos de introducir nuevamente el trabajo forzoso (NICHOLLS, 1998).

La intervención de Estados Unidos implantó un escenario político-militar de control para asegurar el desarrollo de negocios en el país (MONTENEGRO, 2013). En consecuencia, en 1918, el Subsecretario de Estado de la Marina de los Estados Unidos, el futuro presidente Franklin Delano Roosevelt, se convierte en el responsable de escribir una nueva constitución para Haití, donde todas las leyes haitiana en que impedían a los extranjeros llegar a ser propietarios de tierras fueron canceladas, allanando el camino para la compra por parte de capitales estadounidenses. ${ }^{7}$

Con la invasión, los Estados Unidos pasaron a controlar las finanzas del país con la promesa de ayuda monetaria como contrapartida. En 1914 más del $44 \%$ de los recursos haitianos en dinero eran destinados a finan-
4. Sólo a nivel introductorio referimos el proceso de dependencia previo a la llamada fase imperialista del capitalismo y al hito de la invasión de 1915.

5. En 1904, el presidente estadounidense Theodor Roosevelt estableció los términos de su Corolario a la Doctrina Monroe: frente a una eventual intervención de una potencia extracontinental en un país latinoamericano por falta de pago de sus deudas, los Estados Unidos podrían intervenir preventivamente para evitarlo, sanear la economía y obligar a ese país a pagar sus deudas, ejerciendo un papel de policía internacional. Roosevelt menciona explícitamente los "países bañados por el Mar Caribe" en el Corolario, consideraba idénticos los intereses de Estados Unidos y de sus vecinos, y sostiene como ejemplo a seguir la intervención estadounidense en Cuba (MOREIRA; OUINTEROS; REIS DA SILVA, 2010).

6. Ya en los prolegómenos de la l Guerra Mundial, Ios banqueros alemanes eran los principales financiadores tanto del pequeño comercio como del propio Estado haitiano. Los alemanes controlaban por entonces el 80\% del comercio y las filiales de las empresas teutonas administraban servicios públicos en Port-au-Prince como la electricidad y los tranvías. Esta presencia en la economía del país caribeño fue una de las motivaciones de la invasión estadounidense de 1915 (SEGUY, 2014).

7. El gobierno norteamericano argumentaba que tales medidas eran beneficiosas para Haití y su progreso, pues ella incentivaría las inversiones de capitales extranjeros en el país. De hecho, hubo un boom de compras de tierras por capitales estadounidenses: la Haytian American Sugar Company compró 7.532 hectáreas, la Haytian Products Company 3.166 hectáreas, y en 1943, la Sociedad Haitiana de Desarrollo Agrícola compró 12.403 hectáreas desplazando a 40.000 familias campesinas (SEGUY, 2014). 
7. En ese contexto, desde el gobierno del presidente Theodor Roosevelt, el imperialismo estadounidense estaba determinado a: 1) expandir los mercados de los capitales estadounidenses en América y Asia; 2) crear un sistema naval de defensa en el Océano Pacífico; 3) controlar Cuba y Puerto Rico; 4) construir un canal en América Centra para conectar el océano Atlántico con el Pacífico; 5) continuar la expansión y la modernización de la marina estadounidense para su accionar a escala internacional; 6) reducir la influencia europea en el Caribe; 7) contener la expansión japonesa en el Pacífico y la influencia alemana en América Latina: y 8$)$ defender la costa este de posibles ataques alemanes (NETO, 2015) ciar la deuda externa. En 1922, el National City Bank of New York compró la deuda, rompiendo la preponderancia francesa en la obtención de esos recursos, vinculando a la vez a Haití a los Estados Unidos (NETO, 2015). ${ }^{7}$

En 1930, ante la impopularidad del régimen colaboracionista de Louis Borno (1922-1930), se celebraron las nuevas elecciones. Los comicios dieron como resultado la victoria a Sténio Vincent para el cargo de presidente. Vincent llegó a un acuerdo con Franklin Roosevelt para la retirada de las tropas y consiguió poner fin a la ocupación en 1934 (NETO, 2015).

La configuración de la dependencia haitiana en el marco

de la "buena vecindad" y la Segunda Posguerra (1934-1957)

A partir de la $\mathrm{VII}^{\circ}$ Conferencia Panamericana realizada en Montevideo en 1933, bajo la presidencia de Franklin Roosevelt, los Estados Unidos impulsaron una política de "buena vecindad" con los países latinoamericanos. En general, se trataba de procurar una alianza hemisférica frente al expansionismo de las potencias del eje Berlín-Roma-Tokio, por lo cual las invasiones fueron sustituidas por gobiernos fuertemente tutelados y alineados a los intereses monopolistas y financieros norteamericanos (MORGENFELD, 2011).

Estos procesos incidieron en la configuración de índices sociales y económicos desfavorables, siendo Haití el país más pobre del continente americano. Durante años, el país caribeño experimentó un empeoramiento de las condiciones de vida de su población, un incremento demográfico significativo que pasó - entre 1930 y 1980 - de unos 2.500 .000 personas a 6.000 .000 de habitantes y un preocupante deterioro de la calidad del suelo en todo el país. Este cuadro, justificó los planes de los gobiernos haitianos y de las misiones extranjeras para detener los perjuicios que sufría el país, aunque los resultados fuesen frecuentemente negativos (NICHOLLS, 1998).

Haití continuó siendo una economía predominantemente agrícola de producción de alimentos para el consumo local a la par que producía cultivos para el mercado externo. El principal producto exportado era el café y registrándose un desarrollo limitado de la producción comercial del azúcar, el algodón y el sisal. Conjuntamente, se experimentaron tentativas de explotación minera de cobre y de bauxita con reducido éxito.

La concentración de las tierras cultivables y de la producción agrícola en el país es más un trazo característico del imperialismo estadunidense en América Latina. Como resultado de la apropiación de tierras por capitales norteamericanos y la expropiación de los campesinos haitianos se registró un intenso éxodo rural y el inicio del proceso de crecimiento acelerado de Port-au-Prince y otras ciudades del país. Esos nuevos elementos, la urbanización y el surgimiento de una nueva mano de obra disponible, se tornaron grandes atractivos para la instalación de empresas estadunidenses en el país, que además de beneficiarse de los privilegios fiscales podían contar con una fuerza de trabajo extremamente barata (D’ANS, 2011).

Sobre la base de la expulsión del campesinado pobre se desarrollaron compañías que poseían plantaciones extensas como la Haytian American Sugar Corporation (HASCO) y se creaba una mano de obra poten- 
cial. De todas maneras, en Haití no se consiguió crear una agroindustria a gran escala similar a la desarrollada en Cuba, Puerto Rico y la República Dominicana (NICHOLLS, 1998).

A partir de la ocupación estadounidense las inversiones norteamericanas de expandieron permitiendo que, aun después de retiradas las tropas del país, Washington supervisara la política del gobierno. En 1941, el arribo de Elie Lescot, ex ministro de gabinete bajo Borno y Vincent, protegido del presidente dominicano Rafael Leónidas Trujillo y ex embajador de Haití en los Estados Unidos, representó un alineamiento total a los intereses estadounidenses. Lescot concedió tierras para la producción de caucho y sisal a la firma Société Haïtienne-Américaine de Développement Agricole (SHADA) - de capital norteamericano - y llevó a Haití a participar en el bando de los aliados de la Segunda Guerra Mundial por pedido de la Casa Blanca, aunque no contribuyó con tropas (NICHOLLS, 1998).

En la posguerra, Haití sufrió algunos períodos de breve dictadura liderados por una junta militar encabezada por Franck Lavaud. En enero de 1946, fue depuesto el presidente Elie Lescot y en agosto fueron celebradas elecciones que llevaron a Dumarsais Estimé a la presidencia. Luego del golpe de Estado de mayo de 1950 contra Estimé, fue electo a finales del mismo año un ex miembro de la junta militar: Paul Eugène Magliore, que desempeñó el cargo de presidente hasta diciembre de 1956 (SMITH, 2009).

La era del duvalierismo (1957-1990)

A finales del decenio de 1950 y al iniciarse el de 1960, la bauxita y el cobre se convirtieron en importantes bienes de exportación. En esa última década, principalmente en Port-au-Prince y sus alrededores, se produjo un incremento acelerado de plantas de montaje y fábricas de industria liviana.

La segunda mitad del siglo XX, está marcada por el régimen de los Duvalier; los gobiernos de François 'Papa Doc' Duvalier (1957-1971) y Jean-Claude 'Baby Doc' Duvalier (1971-1986). En 1957, François Duvalier llegó al poder con el apoyo de grupos heterogéneos, entre los que resultaron clave los políticos y líderes negros de la pequeña burguesía. Buena parte de este segmento estaba compuesto por propietarios de unidades rurales de mediana extensión, comerciantes que intermediaban -llamados spéculaters - en la compra del café entre campesinos y las compañías exportadoras, y sacerdotes del vudú (hougans) e ideólogos que reafirmaban el valor de racial de la población negra (noiristes) (NICHOLLS, 1998).

A la persistente corriente de migrantes económicos, se le sumó la situación de los exiliados políticos de la época duvalierista. De todas maneras, según estadísticas dominicanas del decenio de 1960, la migración económica hacia República Dominicana siguió siendo persistente: de alrededor de 60.000 trabajadores de los centrales azucareros, por lo menos 30.000 eran haitianos (CORTEN, 1973). Esta fenómeno, cuya masividad se remonta a los años finales de la década de 1910 (ACOSTA, 1973), tendrá una persistente continuidad debido a los intereses de las clases dominantes haitianas y dominicanas en beneficiarse del carácter precario e ilegal de estos trabajadores haitianos en "la industria azucarera, las plantaciones de café, cacao y arroz, así como en las actividades de construcción” (VERAS, 1988, p. 203). 
8. Al mismo tiempo, en el contexto de la disputa bipolar entre Estados Unidos y la Unión Soviética, el gobierno de 'Papá Doc' Duvalier significó una defesa de los negocios estadunidenses y una posición de combate al comunismo (NETO, 2015).

9. Denominación popular otorgada a los Voluntarios de la Seguridad Nacional, "que ejercieron una constante vigilancia de la sociedad en beneficio del régimen en tanto combinaban los roles de instrumento de propaganda, de policía (apenas) secreta, de milicia popular, $y$ casi de partido único en el plano político." (D'ANS, 2011, p. 223)

10. "El movimiento del capital intersectorial continúa con la concentración de capital, y además aumenta el grado monopolización de la economía. (...) el total de plusvalía no necesariamente cambia con el aumento de la monopolización, pero sí hay una redistribución de la plusvalía del sector competitivo al más monopolizado. Las presiones competitivas continúan, como por ejemplo durante la década de los años setenta, razón por la cual la industria estadounidense se concentra en el Caribe y Centroamérica" (HEROLD, 1988, p. 59).

11. Reagan lanzó en 1982, en el seno de la OEA, la Iniciativa para la cuenca del Caribe (ICC), elaborada con la justificación de "una solución para la crítica situación económico-política y social que enfrenta el área caribeña y centroamericana." (EDWARD, 1988, p. 265). De modo general, el objetivo principal era transformar la región del Caribe en un espacio productor de mano de obra barata enfocado en industrias ensambladoras,

maquilas y de exportación agroalimentaria. La ICC canalizó la asistencia económica y militar suplementaria a la región, de la cual el $15 \%$ se destinó a fines militares en 1982
Con todo, el régimen de 'Papa Doc'- de retórica antiestadounidense - mantuvo una relación con Washington no exenta de tensiones. ${ }^{8} \mathrm{La}$ Casa Blanca no reconoció el segundo mandato de François Duvalier iniciado en 1962- y rebajó el nivel de representación diplomática. Durante el gobierno de John Fitzgerald Kennedy (1961-1963), se suspendieron el envío de fondos oficiales en concepto de ayuda internacional y se

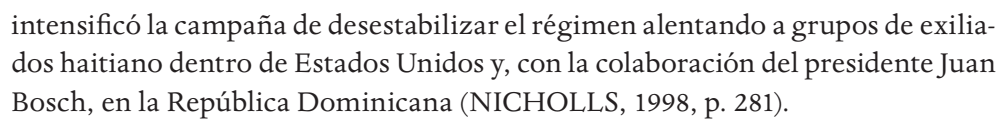
dos haitiano dentro de Estados Unidos y, con la colaboración del presidente Juan Bosch, en la República Dominicana (NICHOLLS, 1998, p. 281).

En 1964, François Duvalier reformó la Constitución y se proclamó presidente vitalicio. Murió en abril de 1971, dejando en el cargo a su hijo Jean-Claude, de 19 años de edad. "En los días que siguieron a la muerte de Duvalier la marina estadounidense patrulló por la isla para evitar invasiones por parte de los exiliados y el traspaso de poder se efectuó son contratiempos" (NICHOLLS, 1998, p. 283).

El gobierno de 'Baby Doc' cultivó las buenas relaciones con las administraciones norteamericanas y, con el apoyo de los Estados Unidos, reabrió la Academia Militar en 1972 y creó los Leopards Corps, una fuerza de contrainsurgencia (MATIJASCIC, 2010). Además, consiguió obtener fondos internacionales para asistencia al desarrollo, que pasaron de "9 millones de dólares en 1970 a 106 millones de dólares en 1980” (NICHOLLS, 1998, p. 283). Estos fondos - fundamentalmente provenientes de Francia y Estados Unidos - contribuyeron al mejoramiento de carreteras. Para mejorar la imagen del régimen, se restringieron las actividades de los tonton macoutes $^{9}$ y el poder de los antiguos partidarios, incrementándose la influencia jóvenes "tecnócratas" provenientes de la elite mulata. En la década de 1970, se instalaron nuevas inversiones estadounidenses en fábricas y plantas de montaje en las que predominó el trabajo intensivo sobre el capital (HEROLD, 1988). ${ }^{10}$

No obstante, Haití se vio afectado la suba de los precios del petróleo en 1979-1980, el azote del huracán David, el descalabro fiscal que llevó a varios funcionarios a la cárcel y la continuidad de un gobierno altamente corrompido que impedía cualquier acumulación de condiciones que permitiera al país salir de la extrema pobreza. De todos modos, el país caribeño mantuvo el apoyo de los Estados Unidos y consiguió que algunos productos de exportación se beneficiaran con la Iniciativa de la Cuenca del Caribe (ICC) impulsada por el gobierno de Ronald Reagan. ${ }^{11} \mathrm{~A}$ la par, unidades navales estadounidenses patrullaban la costa de Haití a fin de detener la avalancha de migrantes que deseaban trasladarse a la costa del estado de Florida en precarias embarcaciones (EDWARD, 1988).

Según el Centro de Corporaciones Trasnacionales de las Naciones Unidas (CCTNU), para 1980, de un total de 44 compañías, el 88,6\% de las filiales de las trasnacionales de Haití eran de origen estadounidense, el 2,3 \% de Francia, el 6,8\% de Holanda y 2,3 \% de otros países europeos. Las manufacturas representaban cerca de la mitad de todas las filiales; el resto se desarrollaba en los demás sectores de la economía (GIRVAN; ODLE, 1988).

Históricamente, los Estados Unidos han propuesto tratados bilaterales de inversiones que contemplan, entre otras cuestiones, compensa- 
ciones en caso de nacionalizaciones. Es decir, se establecen las condiciones legales y fiscales favorables a la inversión de las corporaciones trasnacionales de origen estadounidense.

Lejos de favorecer el desarrollo económico y social que se plantean en las fundamentaciones de la ICC (BORGES, 1985), las inversiones se orientaron fundamentalmente hacia operaciones de ensamblaje con interés en aprovechar el bajo precio de la fuerza de trabajo y las favorables condiciones de negocios (EDWARD, 1988).

Vale detenerse en la observación de Girvan y Odle sobre los intereses de las grandes transnacionales en el Caribe. Los autores sostienen que pueden enumerarse las siguientes funciones en el entramado de la economía internacional:

\begin{abstract}
“i) fuente de materias primas y semiprocesadas de gran importancia industrial y militar; ii) lugar propicio de inversiones para la actividad manufacturera dirigida a las sustitución de importaciones; iii) zona de exportación manufacturera basada en la utilización de mano de obra barata; iv) lugar propicio de inversiones para las actividades bancarias, financieras, turísticas y de servicios, y v) "paraíso" fiscal y centro bancario ultramarino” (GIRVAN; ODLE, 1988, p. 27).
\end{abstract}

A lo que hay que agregar que Haití, como muchos otros países del mundo, también sirve como reserva de recursos a utilizar por las potencias en los momentos oportunos y punto geoestratégico de seguridad de los Estados Unidos.

En el decenio de 1980 podían considerarse las siguientes inversiones estadounidenses en Haití: Toys (relleno de juguetes), TRW (electrónicos), Sperry Gyroscope (ensamblado de partes de giroscopio), A.C. Nielsen (cupones de tiendas), Sperry Univer (electrónicos), IBM (electrónicos), Honeywell (electrónicos), Rawlings división of Figgie Int. (baseball), Allied Ind. División de Halliburton (electrónicos), Worth Sports (deportes), Designatronics (Electrónicos), Spaulding Division of Questor (Baseball y ropa), y Wilson Sports division of Pepsico (deportes) (HEROLD, 1988). Puede resaltarse que, para el decenio de 1980, la producción de pelotas de béisbol se destacó entre estas industrias (NICHOLLS, 1998).

El movimiento de 1985-1986 que llevó a la destitución de Jean Claude Duvalier comenzó en Gonaïves y de allí se propagó a las otras provincias para luego manifestarse en la capital. En ese marco, Estados Unidos cortó su sostén económico a la dictadura (manteniendo sólo los fondos en concepto de ayuda humanitaria) y cuestionó la política de derechos humanos (HIRST, 1996). Así, 'Baby Doc' abandonó el país el 7 de febrero de 1986, asumiendo un Conseil National de Gouvernement (CNG), controlado por militares, cuyo jefe era el general Henri Namphy. El CNG estableció un calendario para redactar una nueva Constitución y convocar elecciones presidenciales en noviembre de 1987 (NICHOLLS, 1998).

De todos modos, las elecciones se realizaron el 17 de enero de 1988 y resultó electo Leslie Manigat, candidato que contó con el apoyo mayoritario del ejército. Manigat - un antiguo duvalierista que rompió con 'Papa Doc' a comienzos de 1960 y luego pasó 25 años exiliado - tomó posesión del cargo el 7 de febrero. El nuevo presidente duró sólo cuatro meses en funciones, dado que fue depuesto por un golpe de Estado en junio de 1988 (NICHOLLS, 1998) y se instaló un régimen militar que llevó 
nuevamente al poder a Henri Namphy. Posteriormente, otros generales organizaron golpes de Estado y sucesivamente se fueron reemplazando en el gobierno de facto hasta recaer el gobierno en la presidenta de la Corte Suprema de Justicia Haitiana: Ertha Pascal-Troulliot (GIRARD, 2004).

En ese sentido, la dominación del Caribe es actualizada a las necesidades del capital estadunidense en período. En el discurso del vicepresidente George Bush en la Conferencia de Miami sobre el Caribe, 5 de diciembre de 1982, se destaca

el $50 \%$ de nuestro comercio pasa por el Caribe a través de estrechos estratégicos
y vías entre estas islas naciones y a través del Canal de Panamá. (...) Queremos
mantener el clima favorable a la inversión extranjera en la región no solamen-
te para proteger las inversiones norteamericanas existentes, sino para alentar
nuevas inversiones en países estables, democráticos, orientados hacia mercados
abiertos, cercanos nuestras costas" (EDWARD, p. 265-266).

La estrategia de la defensa de la democracia en el ámbito internacional guía las acciones, muchas veces unilaterales de los Estados Unidos en el campo externo. Los recursos de poder del país y las amenazas de castigo por no acatamiento permiten que su influencia sea ejercida de forma indirecta a través del ejercicio de una diplomacia coercitiva y, de ser necesario, de forma directa a través de una acción militar (GEORGE; SIMONS, 1994).

A partir del triunfo de Aristide: inestabilidad política, intervenciones militares, inversiones extranjeras y comercio exterior dependiente

En noviembre de 1990, Jean Bertrand Aristide fue elegido con el $67 \%$ de los votos y asumió la presidencia de Haití en el mes de febrero de 1991. A partir de entonces, Aristide enfrentó numerosas obstáculos para concretar las reformas prometidas durante la campaña presidencial. Contó con la oposición abierta de los militares frente a los planes de creación de una fuerza policial independiente y a una revisión más severa sobre las violaciones a los derechos humanos. Al mismo tiempo, el empresariado disgustaba de sus propuestas de incremento del salario mínimo (HERNÁNDEZ, 2010).

Tampoco en el plano externo contó con apoyos. Estados Unidos no coincidía con su perfil de reformista político y social y sus críticas al trato estadounidense de los refugiados haitianos. Así mismo, Aristide cuestionó la política migratoria de la República Dominicana. Por otra parte, su adhesión a "la teología de la liberación generó una preocupación compartida por los militares, la jerarquía católica conservadora e incluso el Vaticano, y contribuyó para debilitar al gobierno" (HIRST, 1996, p. 60).

En ese marco, el 30 de septiembre de 1991, se produjo un golpe de Estado encabezado por los generales Raoul Cédras y Phillipe Biamby, y el jefe de policía Michel François. Aristide contó con apoyó internacional para recobrar el poder, fundamentalmente de la iniciativa diplomática interestatal encabezada por Canadá, Francia, Estados Unidos y Venezuela que ejerció presión para el restablecimiento de la democracia en el país.

La reunión de ministros de Relaciones Exteriores de la Organización de Estados Americanos (OEA) condenó el golpe y recomendó el empleo de 
sanciones económicas y diplomáticas contra Haití. Mientras tanto, Cédras se mantuvo como el hombre fuerte del país hasta 1994, imponiendo presidentes provisionales que manejaba a voluntad. Fue sucedido sucesivamente por Joseph Nerette, Marc Bazin y Émile Jonassaint. La Comisión Interamericana de Derechos Humanos, por pedido de Aristide, consignó observadores internacionales para Haití a fin de monitorear y notificar sobre las violaciones de los derechos humanos (SEITENFUS, 2016).

La administración de George H. Bush (1989-1993), a través de la actuación de la OEA en los asuntos haitianos, consiguió no involucrarse directamente en la crisis. En este contexto, la OEA incrementó las medidas coercitivas contra el régimen de Cédras (HIRST, 1996). ${ }^{12}$

Hacia fines de 1992, ninguna de las sanciones de la OEA había obtenido resultados aceptables. Haití conseguía recibir sin problemas los productos procedentes de América Latina, Europa y países africanos. Además, con la pavimentación de las rutas que conectaban con la República Dominicana, las comunicaciones terrestres con ese país habían mejorado. Por otra parte, la violencia policial y la violación de los derechos humanos continuaban como en los tiempos de los Duvalier (SEITENFUS, 1994).

En diciembre de 1992 fue designado el argentino Dante Caputo como representante en Haití del secretario general de la ONU, Boutros-Ghali y representante especial del Secretario General de la OEA. La posición de Caputo significó un mayor involucramiento de la ONU, quien comenzó a defender una intromisión militar multilateral como una medida legítima para resolver la crisis (HIRST, 1996).

Ya con la administración norteamericana del presidente Bill Clinton, el traspaso del caso haitiano de la OEA al Consejo de Seguridad (CS) de la ONU delineó las posibilidades de una resolución drástica para restablecimiento del orden democrático. Frente a la negativa de negociar de las autoridades haitianas, el CS de la ONU impuso un embargo petrolero y de armas al país (GIRARD, 2004).

Estas últimas coerciones consiguieron que el régimen cediera, el general Cédras aceptó firmar con Aristide el Acuerdo de la Isla del Gobernador (Estados Unidos), el 3 de julio de 1993, comprometiéndose a restaurar el gobierno constitucional. Además, se convino el establecimiento de la Misión de las Naciones Unidas en Haití (UNMIH) para colaborar en la modernización de las fuerzas armadas y la instauración de una nueva fuerza policial (HIRST, 1996).

Sin embargo, un nuevo incremento de la violencia política impulsada por los militares haitianos,

\footnotetext{
fueron acompañadas por manifestaciones nacionalistas con un fuerte componente antinorteamericano. El pico de mayor tensión de este retroceso se produjo cuando miembros de fuerzas paramilitares del Front pour l'Avancement et le Progres Haiten (FRAPH) impidieron el desembarco de un contingente militar de la UNMIH en Puerto Príncipe (HIRST, 1996, p. 65).
}

Desde octubre de 1993, Estados Unidos se decidió a asumir el liderazgo explícito de la crisis haitiana. El restablecimiento de las sanciones se convirtió en parte de una maniobra más vasta que tenía como meta la intervención militar; el uso de la diplomacia coercitiva iría se transformando en uso directo de la fuerza.
12. Con el golpe de Estado, Haití pasó por un período de tres años de extrema violencia civil y persecución política. Un ambiente ideal para legitimar las sucesivas intervenciones de la $\mathrm{ONU}$ en el país caribeño, apoyadas por los Estados Unidos a partir de 1993 (HERNÁNDEZ, 2010). 
13. De acuerdo a Herz y Ribeiro Hoffman (2004), las Misiones de Paz asumen un carácter multidimensional:

1) ganan autorización para fines más

allá de la legítima defensa; 2) no implica o consentimiento de todas las partes involucradas; 3 ) involucran la participación de varias agencias de la ONU, organizaciones internacionales regionales y Organizaciones No Gubernamentales de Alcance Transnacional (ONGATS); y 4) establecen prerrogativas para la interferencia en asuntos domésticos (HERZ; HOFFMAN, 2004).

En ese sentido, en consonancia con los intereses de propagación de las democracias de mercado presente en la política externa norteamericana a partir de la pos Guerra Fría, las misiones de paz pueden ser entendidas como una imposición de la "Paz Liberal" (Paris, 2004; Pugh, 2005), a través de la transposición de los estándares económicos y políticos neoliberales, adecuando los territorios dependientes a las necesidades del capital transnacional a lo largo del tiempo.

14. Esta unidad "cuenta con el antecedente macabro de haber operado en la mayor parte de intervenciones que los Estados Unidos ha realizado en los últimos 100 años en distintos lugares del mundo, como en las de Vietnam, Bosnia-Herzegovina, Afganistán e Iraq, y en nuestro continente participó en las invasiones a República Dominicana (1965), Granada (1983) y Panamá (1989)" (CANTOR; NOVOA, 2014, p. 144).
El régimen de Cédras buscó evitar por todos los medios mejorar su imagen internacional y disuadir al CS de la ONU de una intervención militar multinacional. Emile Jonassaint fue elegido por el Parlamento como presidente interino, con la promesa de convocar elecciones en los meses siguientes. De todos modos, Jonassaint declaró el Estado de sitio y las violaciones de derechos humanos continuaron (GIRARD, 2004).

El 18 de septiembre de 1994, Clinton envió a Haití al ex presidente Jimmy Carter, al general Colin Powell y al senador Sam Nunn consiguiendo firmar con Jonassaint el Acuerdo de Por-au-Prince. Siguiendo este acuerdo, se dio inicio a la Operación "Uphold Democracy", la intervención militar de Estados Unidos y la ONU en Haití que permitió la entrega del gobierno a Aristide. Tras la partida de Cédras al exilio, Aristide retornó al país en octubre de 1994 y culminó su mandato presidencial en febrero de 1996 (HIRST, 1996).

Aristide fue sucedido por uno de sus colaboradores: René Préval. Este ingeniero agrónomo haitiano, quien había conseguido una mayor popularidad a partir de su cargo de primer ministro, ocupó la presidencia hasta febrero de 2001. Tras las presiones del FMI, Préval adoptó reformas de signo neoliberal y privatizó empresas estatales (SEITENFUS, 2016).

En 2001, las elecciones llevaron Aristide a retornar a la presidencia del país. En ese entonces, el nuevo presidente orientó su política exterior hacia la confluencia con Cuba y a la Venezuela presidida por Hugo Chávez. Estos realineamientos disgustaron a los Estados Unidos y estimularon a los grupos de oposición a adoptar posiciones más radicales contra el gobierno y el surgimiento de grupos armados. En febrero de 2004, un nuevo levantamiento de militantes opositores consumó el golpe de Estado, llevando a Aristide a un exilio de 7 años (HERNÁNDEZ, 2010).

Luego del derrocamiento de Aristide, la presidencia interina fue ejercida por Boniface Alexandre, por entonces presidente del Tribunal Supremo de Justicia hasta mayo de 2006. Paralelamente, en 2004 Haití fue azotada por una tormenta, dos tormentas de 2007 , y cuatro huracanes en 2008, en todas las ocasiones el país sufrió miles de muertos y damnificados (LORENZO; REINOSO, 2011).

Durante el gobierno de Alexandre fue solicitada una nueva intervención de la ONU. Así, al amparo de la resolución 1542 del CS de la ONU del 30 de abril de 2004, fueron creadas las fuerzas de la Misión de Estabilización de las Naciones Unidas en Haití (MINUSTAH) ${ }^{13}$. Esta ocupación se ha extendido hasta la fecha y el retiro total de los efectivos militares de la ONU ha sido anunciado para octubre de 2017 (HERNANDEZ, 2017).

En febrero de 2006, René Préval ganó nuevamente las elecciones, siendo investido en mayo del mismo año. Durante el segundo gobierno de Préval, el país fue arrasado por un terremoto en enero de 2010, como consecuencia murieron unos 220 mil haitianos y miles de personas quedaron heridas y discapacitadas.

Apenas a una semana del terremoto, Haití constituyó el escenario de una intervención directa de la IV Flota. Estados Unidos desplazó un portaaviones, aviones, dos buques anfibios, 23 navíos y otros artefactos bélicos. Así mismo, desembarcaron unos 16 mil soldados - incluida la $82^{\circ}$ División Aerotransportada ${ }^{14}$ - que ocuparon el aeropuerto de Port- 
au-Prince y tomaron el control de las pocas edificaciones públicas que sobrevivieron al terremoto (CANTOR; NOVOA, 2014).

En 2011, sobre el final de la administración de Préval, se admitió el regreso de Aristide, quien volvió al país en el mes de marzo. El mismo año, luego de controvertidas contiendas electorales, llegó a la presidencia Michel Martelly. En 2015, la crítica situación interna - un 70\% de desocupación, aumento exponencial del número de emigrantes y de denuncias de corrupción gubernamental - derivó en la suspensión del ballotage. Martelly dejó el gobierno en febrero de 2016 sin sucesor electo y asumió interinamente el senador Jocelerme Privert. Recientemente, en noviembre de 2016 se realizaron elecciones presidenciales con una participación del 21\% del electorado. El jueves 15 de diciembre de 2016, en las calles de Port-au-Prince, miles de personas se movilizaron contra los resultados preliminares, calificando este proceso de "golpe de Estado electoral" (SÉNAT, 2016). En enero de 2017, Jovenel Moïse - candidato del Parti Haïtien Tét Kale (PHTK) -, apoyado por el ex presidente Martelly, fue declarado presidente electo, asumiendo la primera magistratura del país en el mes siguiente (WIMER, 2016; WIMER, 2017).

En los últimos años, según el trabajo de García Lorenzo y Martínez Reinoso, "13 de los 15 sectores económicos más importantes de Haití tienen como inversionista principal a importantes consorcios estadunidenses" (LORENZO; REINOSO, 2011, p. 283). Además, la Legislación HOPE/ HELP ha permitido facilidades en régimen de franquicia arancelaria para el acceso de los textiles haitianos al mercado estadounidense, con lo cual ha incentivado las inversiones extranjeras en el sector (OMC, 2015b). ${ }^{15}$

En los últimos años, están en el centro de los intercambios comerciales los productos no legales: los narcóticos. El presidente Barack Obama ha otorgado un multimillonario financiamiento a la denominada Iniciativa de Mérida (México and Central America Security Cooperation Initiative) con el objetivo de controlar el narcotráfico y el crimen organizado en Centroamérica, Haití y República Dominicana (SALAZAR, 2011). Haití está dentro del corredor del Caribe, desde donde entra, según la Drug Enforcement Administration (DEA), entre un 35\% a un $40 \%$ de la droga a los Estados Unidos (GARCÍA, 2011).

El comercio exterior de Haití se desarrolla de forma concentrada, tanto en su organización geográfica como por mercaderías. Entre un $80 \%$ y un $96 \%$ de las exportaciones haitianas se realizan con los Estados Unidos. En 2014, los Estados Unidos representaron un 85,6\% de las ventas externas de los productos de origen haitiano, secundado por Canadá con un 3,4\% y México con un 2\% como destino de las mercaderías del país caribeño. En 2015, unos US\$ 950 millones en concepto de exportaciones haitianas se dirigieron a Estados Unidos, es decir el 95\% del total (OMC, 2015a).

La estructura del comercio exterior es altamente deficitaria para Haití. En 2015, la tasa de cobertura fue del 29\%. Las exportaciones alcanzaron los US\$ 990 millones mientras que las importaciones rondaron los US\$ 3.400 millones. Respecto a las relaciones comerciales con Estados Unidos, Haití mantiene un déficit constante aunque en este caso - en el mismo año - la tasa de cobertura fue del 83\% (OMC, 2015a).
15. En 2006, los Estados Unidos aprobaron la Ley de Oportunidades Hemisféricas de Haití (HOPE, por sus sigla en inglés), permitiendo a la industria textil beneficiarse por nuevas preferencias arancelarias. Estas preferencias fueron ampliadas aún más en 2008 por la legislación conocida como HOPE II y, en 2010, por el Programa de Alza Económica de Haití (conocido como HELP, por su sigla en inglés) (OMC, 2015b). 
Respecto a las importaciones, Estados Unidos concentró en 2009 , un $33,7 \%$ de los US\$ 2.352 millones en mercancías importadas. En 2014, los productos de origen estadounidense representaron un $32,9 \%$ de los US\$ 3.877 millones importados por Haití. En 2015, las importaciones la potencia norteamericana alcanzaron los US\$ 1.140,6 millones, representando $33,5 \%$ de las compras al exterior de la nación caribeña (OMC, 2015a).

Más del $85 \%$ de sus exportaciones son manufacturas textiles y de cuero; $3 \%$ de productos químicos y $3,5 \%$ de productos agrícolas (LORENZO; REINOSO, 2011). Los productos alimenticios ocupan un lugar predominante en las importaciones (un 50\% de las importaciones haitianas) a causa del explosivo crecimiento demográfico y del declive del sector agrícola afectado por las sucesivas catástrofes naturales. En este sentido, vale destacar que sólo los productos agrícolas ocupan un $22 \%$ de las importaciones (OMC, 2015b). Así, la situación reciente de Haití es coincidente con el colapso del modelo primario exportador tradicional y una nueva inserción internacional que viven las economías centroamericanas y caribeñas, basados en las exportaciones de productos manufacturados de bajo costo (SEGOVIA, 2005).

Vale destacarse la participación de la República Dominicana y la República Popular China en la estructura de las importaciones. Los productos dominicanos pasaron de representar un $26,3 \%$ a un $36,7 \%$ entre 2009 y 2014 respectivamente. Las mercancías chinas, entre los mismos años, saltaron de un $6,3 \%$ a un 10,1 \% (OMC, 2015a). En este sentido, es sugestiva la participación de la República Popular China en la MINUSTAH y la intervención en el país caribeño a través de proyectos de mejoramiento del sistema sanitario y suministro de equipamiento médico. Además, ha contribuido con asistencia financiera para la reconstrucción del país luego del terremoto de 2010 (PEÑA; ALFONSO, 2015)

Conclusiones

Nuestro estudio muestra que la condición dependiente de Haití está atravesada por la proyección de la estrategia imperialista de los Estados Unidos. Se percibe a lo largo de la historia haitiana una actualización de las acciones estadunidenses en el país procurando consolidar condiciones políticas, institucionales y culturales necesarias para la profundización del control económico y el desarrollo de los intereses del capital norteamericano en el país caribeño. Estrategias que pasan por intervenciones militares directas en el siglo XX a la utilización de las 'Misiones de Paz' como instrumento de mantenimiento y profundización de la subordinación haitiana al imperialismo. El actual estado de desmantelamiento institucional, superexplotación de la mano de obra, la ausencia de condiciones económicas para la construcción de un proyecto nacional de desarrollo, crisis humanitaria, caos social y toda suerte de conflictos estructurales, hicieron de Haití el país más pobre de América Latina.

El caso de Haití, se torna un caso que sirve para desenmascarar la retórica del imperialismo estadunidense en el orden internacional, substrato explicativo de las acciones de los Estados Unidos en el mundo, no 
podrá ser desvelado sin una lectura de las necesidades del capital estadounidense para expandirse globalmente en cada período.

Concretamente, podemos caracterizar a la injerencia estadounidense en Haití según rasgos principales de la dependencia haitiana a lo largo del siglo XX y lo que va del siglo XXI: a) la economía del país caribeño ha sido atravesada por la presencia de grandes conglomerados estadounidenses que dominaron diferentes sectores de forma monopólica $u$ oligopólica; b) el capital financiero estadounidense ha controlado su deuda externa y principales instituciones; c) su territorio fue disputado por el capital estadounidense como escenario de inversiones y acaparamiento de su comercio exterior (principalmente desplazando al capital alemán y francés y, en la actualidad, trabando la expansión del capital chino); d) sus tierras cultivables y recursos naturales fueron colocadas a disposición de la extracción de plusvalía por parte de los intereses norteamericanos provocando la expropiación masiva de campesinos haitianos provocando el éxodo rural y la aglomeración de la población empobrecida en Portau-Prince; e) las actividades de reconstrucción de Haití, luego de los devastadores huracanes y el terremoto, están colocadas al servicio del imperialismo estadounidense; $f$ ) el establecimiento de maquilas permite a los capitales norteamericanos aprovechar la fuerza de trabajo barata y los menores costos de producción del país caribeño; g) la conversión de Haití en un punto geoestratégico sobre el Caribe permite a los Estados Unidos operar fuerzas militares y de inteligencia en la región.

\section{Referencias}

ACOSTA, M. El contenido Económico y Político del Racismo antihaitiano. In: VILAS, C.; CORTEN, A.; ACOSTA, M.; DUARTE, I. Imperialismo y clases sociales en Caribe. Buenos Aires: Cuenca Ediciones, 1973, p. 115-154.

BORGES, A. G. Introducción a la economía de la Cuenca del Caribe. México: UNAM, 1985.

CANTOR, R. V.; NOVOA, F. M. Colombia y el imperialismo contemporáneo, Bogotá: Ocean Sur, 2014.

CASTOR, S. Migración y relaciones internacionales: el caso dominicano-haitiano. México: UNAM, 1983.

CORTEN, A. Haití: estructura agraria y migración de trabajadores a los centrales azucareros dominicanos. In: VILAS, C.; CORTEN, A.; ACOSTA, M.; DUARTE, I. Imperialismo y clases sociales en Caribe. Buenos Aires: Cuenca Ediciones, 1973, p. 85-114.

D’ANS, A. M. Haití, paisaje y sociedad. Santiago de Cuba: Oriente, 2011 [1987].

EDWARD, I. J. Variantes intervencionistas en la 'Cuenca del Caribe'. In: PIERRE-CHARLES, G. Capital transnacional y trabajo en el Caribe. México: Plaza y Janés, 1988, p. 263-281.

GARCIA, E. De la plantación al resort: El Caribe en la era de la globalización. In: MARTÍNEZ, M.; LAGUARDIA, J. El Caribe en el siglo XXI, coyunturas, perspectivas y desafíos. Habana: Editorial de Ciencias Sociales, 2011, p. 176-194.

GEORGE, A.; SIMONS, W. The limits of coercitive diplomacy. Boulder: Westview Press, 1994. GIRARD, P. Clinton in Haiti. New York: Palgrave Macmillan, 2004.

GIRVAN, N.; ODLE, M. Papel de las compañías trasnacionales en las economías caribeñas In: PIERRE-CHARLES, G. Capital transnacional y trabajo en el Caribe. México: Plaza y Janés, 1988, p. 19-46.

HERNÁNDEZ, C.S. Haití, Aristide, y la política exterior y militar de los Estados Unidos (1990-2010). Nómadas. Revista Crítica de Ciencias Sociales y Jurídicas. Madrid, v. 25, n. 1, 2010. Disponível em: http://www.redalyc.org/articulo.oa?id=18112179004. Acceso em: 13 de mai. 2017. 
HERNÁNDEZ, M. Entrevista a Henry Boisrolin del Comité Democrático Haitiano: 'Haití sigue siendo un país ocupado'. Resumen Latinoamericano, 4 de mayo de 2017. Disponível em: < http://www.resumenlatinoamericano.org/2017/05/04/entrevista-a-henry-boisrolin-del-comite-democratico-haitiano-haiti-sigue-siendo-un-pais-ocupado/> Acceso em: 13 mai. 2017.

HEROLD, M. W. Inversiones y desinversiones mundiales de las compañías transnacionales estadounidenses: implicaciones para el Caribe y Centroamérica. In: PIERRE-CHARLES, G. Capital transnacional y trabajo en el Caribe. México: Plaza y Janés, 1988, p. 47-72.

HERZ, M.; HOFFMANN, A. Organizações internacionais: história e práticas. Rio de Janeiro: Campus/Elsevier, 2004.

HIRST, M. Democracia, seguridad e integración: América Latina en un mundo en transición. Buenos Aires: Norma, 1996.

LENIN, V. El imperialismo, etapa superior del capitalismo. In: Obras Completas, Bs. As, Cartago, 1970 [1916], T. XXIII, p. 298-425.

LORENZO, T. G.; REINOSO, M. M. Algunas lecciones de Haití. Necesidad de cooperación para el desarrollo. In: MARTÍNEZ, M.; LAGUARDIA, J. El Caribe en el siglo XXI, coyunturas, perspectivas y desafíos. Habana: Editorial de Ciencias Sociales, 2011, p. 281-301.

MARINI, R. M. Dialéctica de la dependencia. México: Era, 1973.

MATIJASCIC, V. B. Haiti: uma historia de instabilidade política. São Paulo: Anais do XX Encontro Regional de Historia: Historia e Liberdade, 2010.

MONTENEGRO, B. M. P. Missão de estabilização das Nações Unidas no Haiti (2004-2011): problemas, progressos e desafios. São Paulo, 2013. Dissertação (Mestrado em Relações Internacionais) - UNESP/UNICAMP/PUC-SP, Programa San Tiago Dantas de Pós-graduação em Relações Internacionais, 2013.

MOREIRA, L.; QUINTEROS, M.; REIS DA SILVA, A. As relações internacionais da América Latina, Petrópolis, Vozes, 2010.

MORGENFELD, L. Vecinos en conflicto: Argentina y Estados Unidos en las Conferencias Panamericanas, 1880-1955. Buenos Aires: Continente, 2011.

NETO, R. M. Imaginando o "outro” e a nação nas relações internacionais: Commentary Magazine, The New Republic e o intervencionismo dos Estados Unidos na Nicarágua e El Salvador (1977-1992). São Paulo, 2015. Tese de Doutorado em Relações Internacionais- UNESP/UNICAMP/ PUC-SP, Programa San Tiago Dantas de Pós-graduação em Relações Internacionais, 2015.

NICHOLLS, D. Haití. In: BETHELL, Leslie, Historia de América Latina. México: Cambridge University/Crítica, 1998 [1990], T. 13, p. 267-294.

ORGANIZACIÓN MUNDIAL DE COMERCIO (OMC), "Informe de Políticas Comerciales" (Informe de la Secretaría de la OMC). 27 de octubre de 2015a. Disponível em: $<$ https://docs.wto. org/dol2fe/Pages/FE_Search/FE_S_S009-DP.aspx?language $=$ S\&CatalogueIdList $=227081,227$ $104,227080,226855,226228,135772,135466,135464,7439,48714 \&$ CurrentCatalogueIdIndex $=7 \& F u 1$ 1 TextHash $=\&$ HasEnglishRecord $=$ True $\&$ HasFrenchRecord $=$ True $\&$ HasSpanishRecord $=$ True $>$. Acesso em: 15 de mai. 2017.

ORGANiZACIÓN MUNDIAL DE COMERCIO (OMC), "Informe de Políticas Comerciales" (Informe de gobierno), 27 de octubre de 2015b. Disponível em: $<$ https://docs.wto.org/dol2fe/ Pages/FE_Search/FE_S_S009-DP.aspx?language $=$ S\&CatalogueIdList $=227081,227104,227080$ ,226855,226228,135772,135466,135464,7439,48714\&CurrentCatalogueIdIndex=6\&FullTextHas $\mathrm{h}=\&$ HasEnglishRecord $=$ True $\&$ HasFrenchRecord $=$ True $\&$ HasSpanishRecord $=$ True $>$. Acesso em: 15 mai. 2017

PANITCH, L.; GIDIN, S. Las finanzas y el imperio norteamericano. In: PANITCH, L.; LEYS, C. Socialist Register 2005: el imperio recargado. Buenos Aires: CLACSO, 2005.

PARIS, R. International peacebuilding and the 'mission civilisatrice'. Review of international studies, v. 28, n. 04, p. 637-656, 2002. Disponível em: < http://journals.cambridge.org/action/ displayAbstract fromPage $=$ online $\&$ aid $=129103 \&$ fileId $=S 026021050200637 \mathrm{X}>$. Acesso em: 16 nov. 2016

PEÑA, J.; ALFONSO, L. Las relaciones de los países de la Comunidad del Caribe (CARICOM) con China: ¿David vs Goliat? In: BONILLA SORIA, A.; MILET GARCÍA, P. China en América Latina y Caribe: escenarios estratégicos subregionales. San José: FLACSO, 2015, p. 275-338.

PUGH, M. The political economy of peacebuilding: a critical theory perspective. International Journal of Peace Studies, p. 23-42, 2005. Disponível em: <https://bradscholars.brad. ac.uk/handle/10454/4181>. Acesso em: 16 nov. 2016. 
ROFMAN, A. Dependencia, estructura de poder y formación regional en América Latina. Buenos Aires: Siglo XXI, 1974.

ROMERO, F. G. El imperialismo y el agro argentino: historia reciente del capital extranjero en el complejo agroindustrial pampeano. Buenos Aires: CICCUS, 2015.

SÁNCHEZ TABARES, R.; ELÍAS MORENO, F. El proceso de cambio de las grandes EMN (Empresas Multinacionales). In: GAMBINA, J.; ESTAY, J. ¿Hacia dónde va el sistema mundial? Impactos y alternativas para América Latina y el Caribe. Buenos Aires: FISyP, 2007, p. 37-50.

SALAZAR, L. S. El gran Caribe: una mirada prospectiva de su coyuntura política. In: MARTÍNEZ, M.; LAGUARDIA, J. El Caribe en el siglo XXI, coyunturas, perspectivas y desafíos. Habana: Editorial de Ciencias Sociales, 2011, p. 3-30.

SEGOVIA, A. El impacto del CAFTA sobre el modelo de desarrollo de Centroamérica. Guatemala: Friedrich Ebert Stiftung, 2005.

SEGUY, F. A catástrofe de janeiro de 2010, a "Internacional Comunitária” e a recolonização do Haiti. Campinas, 2014. Tesis de Doctorado en Sociología. Universidade Estadual de Campinas. Instituto de Filosofia e Ciências Humanas.

SEITENFUS, R. Haiti. Porto Alegre: Solivros, 1994.

SEITENFUS, R. Reconstruir Haití: entre la esperanza y el tridente imperial. Santo Domingo: CLACSO, 2016.

SÉNAT, J. D. Lavalas et Pit Dessalines se rejoignent sur le beton. Le Nouvelliste, 16 de diciembre de 2016. Disponível em: <http://lenouvelliste.com/lenouvelliste/article/166444/Lavalas-et-Pitit-Desalin-se-rejoignent-sur-le-beton>. Acesso em: 18 dez. 2016.

SMITH, M. Red \& Black in Haiti: Radicalism, Conflict, and Political Change, 1934-1957. Chapel Hill: University of North Carolina Press, 2009.

TROTSKY, L. Historia de la Revolución Rusa. Buenos Aires: Antídoto, 2006 [1932], T. 1.

VERAS, R. A. El fenómeno migratorio haitiano en la República Dominicana. In: PIERRE-CHARLES, G. Capital transnacional y trabajo en el Caribe. México: Plaza y Janés, 1988, p. 203-261.

WIMER, F.R. El cimbronazo haitiano. Marcha, 22 de diciembre de 2016. Disponível em: <http://www.marcha.org.ar/33765-2/>. Acesso em: 23 mai. 2017.

WIMER, F.R. Haití: Jovenel Moïse fue declarado presidente electo. Marcha, 10 de enero de 2017. Disponível em: <http://www.marcha.org.ar/jovenel-moise-declarado-presidente-electo-de-haiti/>. Acesso em: 23 mai. 2017.

WOOD, E. M. Empire of Capital. New York: Verso, 2005.

YARMOLINSKY, A. The military establishment: it's Impact on American Society. New York: Harper and Row, 1971. 